\title{
Removal of Mercury(II) from Aqueous Solutions by Adsorption on Poly(1-amino-5-chloroanthraquinone) Nanofibrils: Equilibrium, Kinetics, and Mechanism Studies
}

\author{
Shaojun Huang, ${ }^{1}$ Chengzhang $\mathrm{Ma}^{2}$ Yaozu Liao, ${ }^{3}$ Chungang Min, ${ }^{1}$ \\ Ping Du, ${ }^{1}$ and Yubo Jiang ${ }^{4}$ \\ ${ }^{1}$ Research Center for Analysis and Measurement, Kunming University of Science and Technology, Kunming 650093, China \\ ${ }^{2}$ School of Materials Science and Engineering, Kunming University of Science and Technology, Kunming 650093, China \\ ${ }^{3}$ State Key Laboratory for Modification of Chemical Fibers and Polymer Materials, College of Materials Science and Engineering, \\ Donghua University, Shanghai 201620, China \\ ${ }^{4}$ Faculty of Science, Kunming University of Science and Technology, Kunming 650093, China
}

Correspondence should be addressed to Shaojun Huang; sjhuang@kmust.edu.cn

Received 30 December 2015; Accepted 25 February 2016

Academic Editor: Régis Guegan

Copyright (C) 2016 Shaojun Huang et al. This is an open access article distributed under the Creative Commons Attribution License, which permits unrestricted use, distribution, and reproduction in any medium, provided the original work is properly cited.

\begin{abstract}
Poly(1-amino-5-chloroanthraquinone) (PACA) nanofibrils were applied as novel nanoadsorbents for highly toxic mercury removal from aqueous solutions. A series of batch adsorption experiments were conducted to study the effect of adsorbent dose, $\mathrm{pH}$, contact time, and metal concentration on $\mathrm{Hg}$ (II) uptake by PACA nanofibrils. Kinetic data indicated that the adsorption process of PACA nanofibrils for $\mathrm{Hg}$ (II) achieved equilibrium within $2 \mathrm{~h}$ following a pseudo-second-order rate equation. The adsorption mechanism of PACA nanofibrils for $\mathrm{Hg}$ (II) was investigated by Fourier transform-infrared (FT-IR) spectra and X-ray photoelectron spectroscopy (XPS) analyses. The adsorption isotherm of $\mathrm{Hg}$ (II) fitted well the Langmuir model, exhibiting superb adsorption capacity of $3.846 \mathrm{mmol}$ of metal per gram of adsorbent. Lastly, we found out that the as-synthesized PACA nanofibrils are efficient in $\mathrm{Hg}(\mathrm{II})$ removal from real wastewater. Furthermore, five consecutive adsorption-desorption cycles demonstrated that the PACA nanofibrils were suitable for repeated use without considerable changes in the adsorption capacity.
\end{abstract}

\section{Introduction}

Heavy metal ions are highly toxic even at low concentrations and can accumulate in living organisms, causing several disorders and diseases. Unlike organic pollutants, heavy metals are nondegradable. Once in the food chain, they are able to accumulate in living organisms and cause extremely high toxicity [1]. As one of the most poisonous metal ions ever discovered, $\mathrm{Hg}$ (II) has been recognized to cause both acute and chronic toxicity to the central nervous system, kidneys, lung tissues, and reproductive system [2]. It may enter the body through gastrointestinal absorption, skin contact, or pulmonary inhalation. After entering the human body, mercury circulates in the blood and is stored in the liver, kidneys, brain, spleen, and bone, thus leading to several health problems such as paralysis, serious intestinal and urinary complexations, dysfunction of the central nervous system, and, in more severe cases of intoxication, death, widely known as the Minamata Bay accident, Japan, in 1956 [3]. Several sources including chloralkali wastewater, oil refineries, power generation plants, paper and pulp manufacturing, rubber processing, fertilizers industries, and similar industries have all contributed greatly to mercury emission into the environment $[4,5]$. It has been included in the list of priority pollutants by the US EPA with a mandatory discharge limit of $10 \mu \mathrm{g} \mathrm{Hg} \mathrm{L}^{-1}$ for wastewater and a maximum accepted concentration of $1 \mu \mathrm{g} \mathrm{Hg} \mathrm{L}^{-1}$ in drinking water $[6,7]$. Effectively removing mercury from water and wastewater is therefore very important and highly desirable.

Among the traditional techniques of removing the heavy metal ions, adsorption method has been widely studied 
because it is easy to operate and can be cost-effective [810]. To date, many adsorbents of $\mathrm{Hg}$ (II) have been examined. New developed adsorbents, including activated carbon [1, $11,12]$, silica [13, 14], marine macroalga [15], goethite [16], bentonite [17], hydroxylapatite [18], multiwalled carbon nanotubes (MWCNTs) $[19,20]$, and poly ( $m$-phenylenediamine) microparticles [21], were demonstrated to be effective for $\mathrm{Hg}$ (II) removal. However, most of these adsorbents suffer from low adsorption capacities and, therefore, low removal efficiencies of $\mathrm{Hg}$ (II). Hence, researchers have been seeking new efficient adsorbents. The polymer adsorbents with polyfunctional groups and small particle size or large surface area are more attractive due to their high capacity and fast rate of adsorption [22, 23].

The adsorbents in nanoscale usually called nanoadsorbents are in particular attractive because of their unique properties including high surface area, large pore volume, high reactivity, and good chemical species selectivity during adsorption process $[24,25]$. Nanoadsorbents are the most promising materials for wastewater treatment and drinking water purification [26-28]. Nanoporous carbon (such as active carbon and multiwalled carbon nanotubes) and oxide minerals (such as iron oxide, aluminium oxide, and titanium oxide) represent two kinds of traditional nanoadsorbents. The surface area of some of these nanoadsorbents could be as high as several hundred to thousand square meters per gram, allowing sufficient contact between adsorbent particles and metal ions. However, limited functional groups present in adsorbents produce weak guest-host interactions thus leading to poor adsorption capacities [29-31]. Some surface modifications or functionalizations are needed in order to improve adsorption performance, as exampled by cysteine functionalized multiwalled carbon nanotubes (Cys-MWCNTs) [19], arginine modified $\mathrm{TiO}_{2}$ nanoparticles [32], thiol-functionalized $\mathrm{Zn}$-doped biomagnetite particles [33], and citrate-coated gold nanoparticles [34]. Although these modifications are expensive and usually produce additional pollution because of the tedious steps involved [35], the modified nanoadsorbents indeed demonstrate strong adsorbability toward several heavy metal ions, but their maximum adsorption capacity, adsorption rate, and stability still need to be improved.

Nanoadsorbents made from polymer nanomaterials are more attractive because they possess not only polyfunctional groups but also high surface area. The previous report showed that poly(1-amino-5-chloroanthraquinone) (PACA) nanofibrils with high surface area could be simply synthesized (Scheme 1) [36, 37]. Nanoscale PACAs possess rigid polymer chains, extended $\pi$-conjugated structures, high charge density, and a large number of electron-rich groups including $\mathrm{NH}-,-\mathrm{N}=,-\mathrm{NH}_{2},-\mathrm{C}=\mathrm{O}$, and $-\mathrm{Cl}$. The rigid polymer chains endow these polymers with excellent solvent resistance while electron-rich polyfunctional groups and mobile $\pi$-electrons potentially offer a strong binding affinity of polymer molecules toward metal cations. Thus, the polyfunctional nanopolymers are expected to be excellent candidates for removal of mercury ions from solutions.

To the best of our knowledge, applying aminoanthraquinone-based polymer nanomaterials for removal of mercury ions has not been reported. Herein, we report that superb adsorption capacities for $\mathrm{Hg}$ (II) were achieved by using PACA nanofibrils as nanoadsorbents. Adsorption mechanism studies indicated that the presence of polyfunctional groups in the polymers, high surface area, and high porosity corresponded to the superb adsorption capacity, improved adsorption kinetics, and excellent metal ion selectivity, as concluded by inductively coupled plasma atomic emission spectrometer (ICP-AES), Fourier transform-infrared (FTIR) spectroscopy, X-ray photoelectron spectroscopy (XPS), transmission electron microscopy (TEM), and BrunauerEmmett-Teller (BET) analyses. Finally, the practicability of PACA nanosorbent for the removal of $\mathrm{Hg}$ (II) ions from chloralkali wastewater was investigated.

\section{Materials and Methods}

2.1. Materials. ACA monomer, $\mathrm{NaClO}$ oxidant, $\mathrm{Hg}\left(\mathrm{NO}_{3}\right)_{2} \cdot \mathrm{H}_{2} \mathrm{O}$, thiourea, $\mathrm{HNO}_{3}$, ethylenediaminetetraacetic acid (EDTA) disodium salt, and other chemicals were procured from Chemical Reagent Corp. in China. All reagents and solvents were of analytical reagent grade and used as received. The PACA nanofibrils were obtained according to our previous reported method [37]. The nanofibril bundles had the diameters of $20-70 \mathrm{~nm}$, lengths of $0.2-$ $3 \mu \mathrm{m}$, apparent density of $0.375 \mathrm{~g} \mathrm{~cm}^{-3}$, bulk density of $0.649 \mathrm{~g} \mathrm{~cm}^{-3}$, and specific surface area of $35 \mathrm{~m}^{2} \mathrm{~g}^{-1}$.

\subsection{Methods}

2.2.1. Batch Adsorption Experiments. Batch adsorption experiments were conducted in $100 \mathrm{~mL}$ conical flasks containing $25 \mathrm{~mL} \mathrm{Hg(II)} \mathrm{solution} \mathrm{at} \mathrm{an} \mathrm{initial} \mathrm{concentration}$ of $10.0 \mathrm{mmol} \mathrm{L}^{-1}$, to which $40 \mathrm{mg}$ polymer nanofibrils were added. The mixture was then magnetostirred at $300 \mathrm{rpm}$ for $24 \mathrm{~h}$ in a water bath at $25^{\circ} \mathrm{C}$. After adsorption, the metal loaded polymer was separated by centrifugation and the concentration of $\mathrm{Hg}$ (II) in the supernatant was analyzed using inductively coupled plasma atomic emission spectrometer (ICP-AES). The adsorbed amount of metal ions on the nanofibrils was calculated according to the following equations:

$$
\begin{aligned}
& Q=\frac{\left(C_{0}-C\right) V}{W}, \\
& q=\frac{C_{0}-C}{C_{0}} \times 100,
\end{aligned}
$$

where $Q\left(\mathrm{mmol} \mathrm{g}^{-1}\right)$ is the adsorption capacity, $q(\%)$ is the adsorptivity, $C_{0}\left(\mathrm{~mol} \mathrm{~L}^{-1}\right)$ and $C\left(\mathrm{~mol} \mathrm{~L}^{-1}\right)$ are the mean ion concentrations before and after adsorption, respectively, $V$ $(\mathrm{mL})$ is the initial volume of the metal ion solution, and $W$ (g) is the weight of the nanofibrils added.

2.2.2. Adsorption Kinetics. A volume of $50 \mathrm{~mL}$ aqueous solution containing $\mathrm{Hg}(\mathrm{II})$ at a concentration of $0.50 \mathrm{mmol} \mathrm{L}^{-1}$ was transferred to a glass-stoppered conical flask. After $40 \mathrm{mg}$ of PACA was added, the solution was magnetostirred $(300 \mathrm{rpm})$ at room temperature $\left(25^{\circ} \mathrm{C}\right)$. After adsorption 


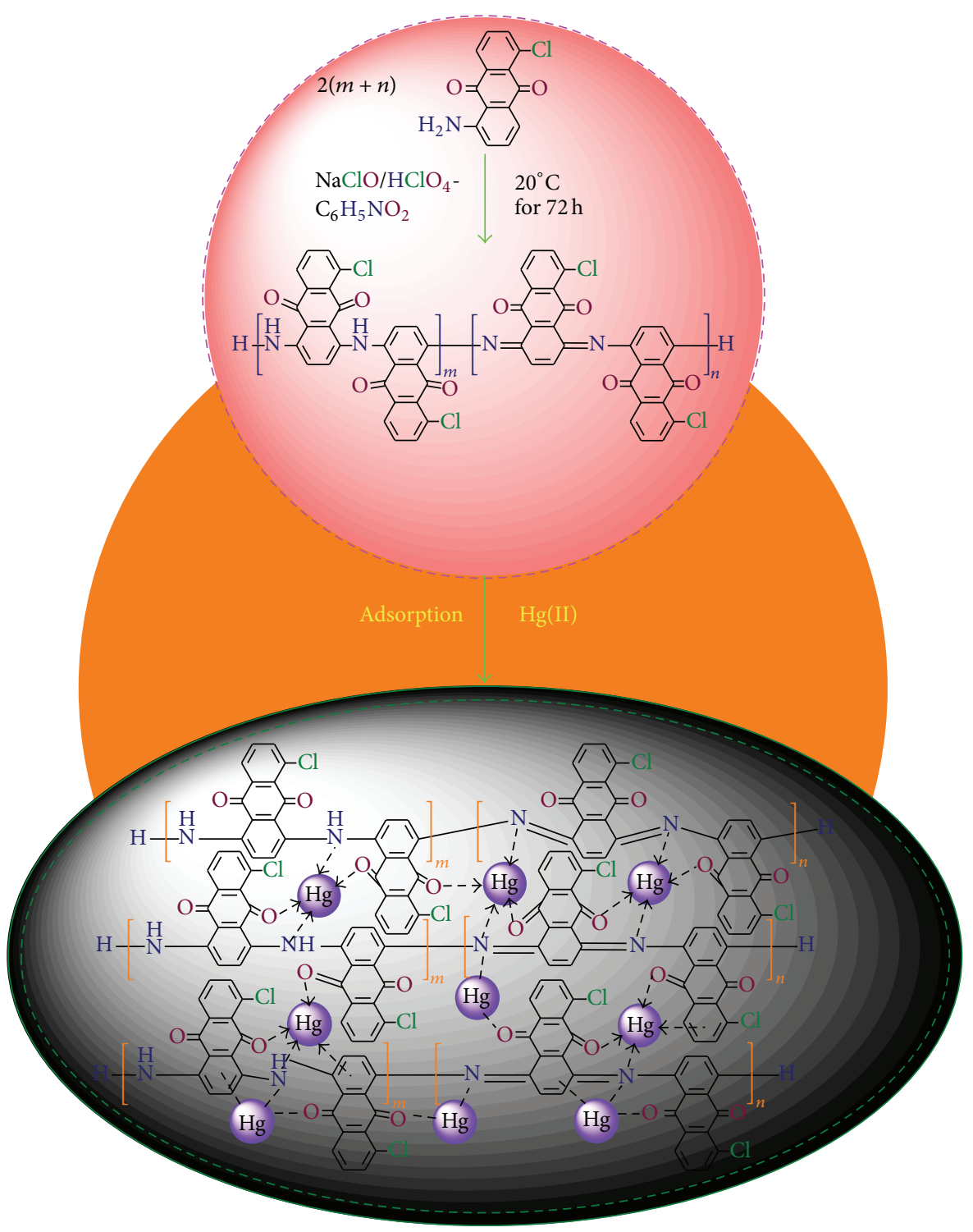

SCHEME 1: Chemical oxidative interfacial polymerization of 1-amino-5-chloroanthraquinone (ACA) and the proposed adsorption mechanism of PACA nanofibrils for $\mathrm{Hg}(\mathrm{II})$.

for $0-240 \mathrm{~min}$, the metal loaded polymer was separated by centrifugation and the concentration of $\mathrm{Hg}(\mathrm{II})$ in the supernatant was analyzed by ICP-AES. By altering adsorption time, the procedure was repeated several times to obtain the amounts of metal adsorbed at certain intervals.

The initial sorption rates and rate constants were calculated and the sorption kinetics were evaluated using pseudo-second-order kinetics based on the equation

$$
\frac{t}{Q_{t}}=\frac{1}{k_{\mathrm{ad}} Q_{e}{ }^{2}}+\frac{1}{Q_{e}} t
$$

where $k_{\text {ad }}\left(\mathrm{g} \mathrm{mmol}^{-1} \mathrm{~min}^{-1}\right)$ is the rate constant of adsorption, $Q_{e}\left(\mathrm{mmol} \mathrm{g}^{-1}\right)$ is the equilibrium adsorption capacity, and $Q_{t}\left(\mathrm{mmol} \mathrm{g}^{-1}\right)$ is the amounts of metal adsorbed at time $t$.

2.2.3. Adsorption Behaviors. The adsorption behaviors of $\mathrm{Hg}$ (II) ion were investigated in aqueous solutions at $\mathrm{pH}$ of $1-7$.
$1.0 \mathrm{~mol} \mathrm{~L}^{-1} \mathrm{NaOH}$ and $1.0 \mathrm{~mol} \mathrm{~L}^{-1} \mathrm{HCl}$ solutions were used to adjust the solution $\mathrm{pH}$. The equilibrium isotherms for $\mathrm{Hg}(\mathrm{II})$ ion were established in aqueous solutions at $\mathrm{pH}$ of 6.0 and $25^{\circ} \mathrm{C}$.

2.2.4. Desorption Behaviors. Desorption of metal ions was performed by mixing PACA-metal complexes and $\mathrm{HNO}_{3}$, thiourea, or EDTA disodium salt eluent solutions of different concentrations, and the mixture was vigorously magnetostirred for $24 \mathrm{~h}$ at $25^{\circ} \mathrm{C}$. The PACA nanoadsorbent was separated by centrifugation and the final metal ion concentrations in the supernatant were analyzed as described in Section 2.2.1. Desorption ratio $(E, \%)$ was calculated from the equation

$$
E=\frac{C_{d} V_{d}}{\left(C_{0}-C\right) V} \times 100
$$


where $E$ is the desorption ratio; $C_{d}\left(\mathrm{~mol} \mathrm{~L}^{-1}\right)$ is the concentration of the metal ion in the desorption solution; $V_{d}(\mathrm{~mL})$ is the volume of the desorption solution; and $C_{0}, C$, and $V$ are the same as defined in Section 2.2.1.

2.2.5. Removal of Mercury from Real Wastewater. In order to survey the capability of PACA nanoadsorbents for removal of $\mathrm{Hg}$ (II) from real wastewater, a batch experiment was conducted on chloralkali wastewater. The wastewater sample was taken from effluent sewage of wastewater treatment plant of Yunnan Salt \& Salt Chemical Co., Ltd. After adjusting the $\mathrm{pH}$ to $6.0,25 \mathrm{~mL}$ of sample was placed in a $100 \mathrm{~mL}$ conical flask and $40 \mathrm{mg}$ of PACA nanoadsorbent was added and magnetostirred for $2 \mathrm{~h}$. After that, the metal loaded polymer was separated by centrifugation and the concentration of $\mathrm{Hg}(\mathrm{II})$ in the supernatant was analyzed by ICP-AES.

2.2.6. Characterization and Measurements. PACA nanofibrils upon adsorption were characterized by FT-IR, XPS, TEM, and BET analyses. The FT-IR spectra of PACA as $\mathrm{KBr}$ pellets were recorded on a Bruker TENSOR 27 Fourier transforminfrared spectrometer (Germany) with resolution of $1 \mathrm{~cm}^{-1}$ by a transmittance method. The XPS spectra were taken by a PHI5000 Versaprobe-II multifunctional scanning and imaging photoelectron spectrometer (Japan) equipped with an $\mathrm{Al}$ $\mathrm{K} \alpha \mathrm{X}$-ray source. The size and morphology of PACA nanofibrils bundles were analyzed by a Tecnai $\mathrm{G}^{2} \mathrm{TF} 30 \mathrm{~S}$-Twin field emission transmission electron microscope (Netherlands). The atomic emission spectra of metal ions in actual water samples were recorded on a PS1000 inductively coupled plasma atomic emission spectrometer made by Leeman Labs, Inc. (USA). The anions in actual water were determined by using DIONEX ICS-3000 ion chromatography (USA). The nitrogen adsorption/desorption measurements at $77.4 \mathrm{~K}$ were performed after degassing the PACA powders under high vacuum at $100^{\circ} \mathrm{C}$ for at least $20 \mathrm{~h}$ using a DZF-6020 vacuum drying oven made by Shanghai Boxun Industry \& Commerce Co., Ltd. (China). The specific surface areas were calculated by applying the Brunauer-Emmett-Teller (BET) model to the adsorption or desorption branches of the isotherms $\left(\mathrm{N}_{2}\right.$ at $77.4 \mathrm{~K}$ ). The apparent (bulk) density of the PACA nanofibrils was determined by the ratio of the mass to a given volume of $2.0 \mathrm{~cm}^{3}$. The fine nanofibrils were put into a plastic tube with a scale and stacked loosely and tightly for the determination of apparent and bulk densities, respectively.

\section{Results and Discussion}

3.1. Effect of Adsorbent Dose. The effect of variation of the adsorbent dose on the removal of $\mathrm{Hg}$ (II) by PACA nanofibrils is shown in Figure 1. Adsorbent dose of PACA was varied from 0.4 to $10 \mathrm{~g} \mathrm{~L}^{-1}$ and equilibrated for $24 \mathrm{~h}$ at an initial $\mathrm{Hg}$ (II) concentration of $10 \mathrm{mmol} \mathrm{L}^{-1}$. It is apparent that the equilibrium concentration in solution phase decreases with increasing adsorbent dose for a given initial $\mathrm{Hg}$ (II) concentration. In other words, increasing the adsorbent dose significantly increased the $\mathrm{Hg}(\mathrm{II})$ ion adsorptivity. Nearly

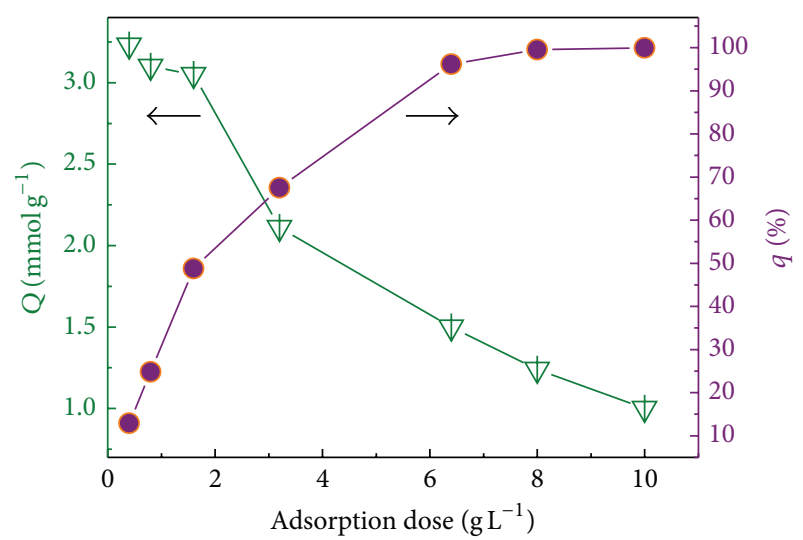

FIGURE 1: Effect of adsorption dose on the adsorption capacity $(Q)$ and adsorptivity $(q)$ of PACA nanofibrils for $\mathrm{Hg}$ (II) ion with an initial concentration of $10.0 \mathrm{mmol} \mathrm{L}^{-1}$ (pH: 5.0) at $25^{\circ} \mathrm{C}$.

complete removal (99.56\%) of $\mathrm{Hg}$ (II) ion from aqueous solution was attained at an adsorbent dose of $8.0 \mathrm{~g} \mathrm{~L}^{-1}$. For adsorbent dose higher than this value, the adsorptivity increased less (Figure 1). Increases in the percentage of the mercury removal with increasing adsorbent dose could be attributed to increases in the adsorbent surface areas, augmenting the number of fresh adsorbent sites available for adsorption, as already reported in several papers $[38,39]$. When adsorbent dose is small, the binding sites on the adsorbent surface are small; thus the adsorptivity is low. Increasing in adsorbent dose leads to increase in active sites of metal binding which means more metal ions are adsorbed. Hence, the adsorptivity increases till saturation. Any further addition of the adsorbent beyond $8.0 \mathrm{~g} \mathrm{~L}^{-1}$ did not cause any apparent change in the adsorptivity. However, by increasing the adsorbent dose, the adsorption capacity firstly decreased slightly and then decreased considerably. The decrease in adsorption capacity can be attributed to the fact that some of the adsorption sites remain unsaturated during the adsorption process [39]. On the other hand, this may be partly due to the fact that the adsorbent gets aggregated and provides less effective surface area for metal binding [40]. In order to obtain complete saturation of the adsorbent surface with $\mathrm{Hg}$ (II) ion, high adsorbent dose was avoided, and all the adsorption studies were conducted at an optimal adsorbent concentration of $1.6 \mathrm{~g} \mathrm{~L}^{-1}$.

3.2. Effect of Solution $p H$. The $\mathrm{pH}$ of the aqueous solution is an important parameter that controls the adsorption of $\mathrm{Hg}$ (II) ion at PACA nanofibrils-water interfaces. Note that neglectable $\mathrm{pH}$ variations were observed after adding PACA nanofibrils to a water with neutral $\mathrm{pH}$, signifying that the nanoadsorbent itself hardly affects the acidity of the $\mathrm{Hg}$ (II) solutions. The effect of $\mathrm{pH}$ value of $\mathrm{Hg}(\mathrm{II})$ solution on the adsorption of $\mathrm{Hg}(\mathrm{II})$ ion using PACA nanofibrils as adsorbents was conducted at $25^{\circ} \mathrm{C}$, as shown in Figure 2. With increasing solution $\mathrm{pH}$ from 1.0 to 5.0 , the adsorption capacity for $\mathrm{Hg}(\mathrm{II})$ increased considerably from 0.39 to $3.05 \mathrm{mmol} \mathrm{g}^{-1}$. However, with further increase in $\mathrm{pH}$ values from 5.0 to 7.0, the adsorption capacity had neglectable changes. This could 


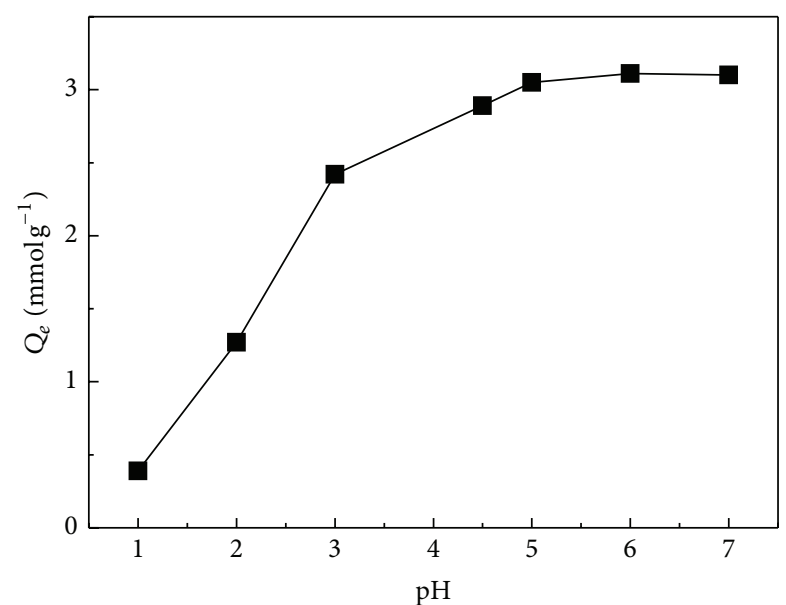

Figure 2: Effect of $\mathrm{pH}$ on the adsorption of $\mathrm{Hg}$ (II) ion with an initial concentration of $10.0 \mathrm{mmol} \mathrm{L}^{-1}$ using $1.6 \mathrm{~g} \mathrm{~L}^{-1}$ dose of PACA nanofibrils at $25^{\circ} \mathrm{C}$.

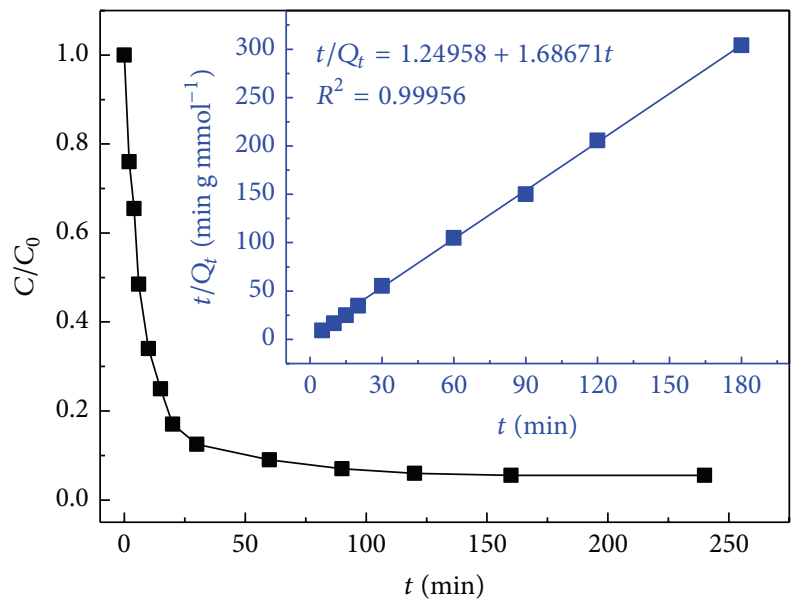

FIgURE 3: Adsorption kinetics of PACA nanofibrils (dose: $0.80 \mathrm{~g} \mathrm{~L}^{-1}$ ) in aqueous solution of $\mathrm{Hg}(\mathrm{II})(\mathrm{pH}: 6.0)$ at a concentration of $0.50 \mathrm{mmol} \mathrm{L}^{-1}$ at $25^{\circ} \mathrm{C}$; the inset indicates the pseudo-second-order adsorption rate.

probably be explained by competition adsorption between metal and hydrogen ions with the binding sites on the surface of PACA nanofibrils [41-43]. At lower $\mathrm{pH}$, binding sites especially amine/amino and carbonyl groups would be more readily protonated, resulting in weak affinity with $\mathrm{Hg}$ (II) ion. At higher $\mathrm{pH}$, binding sites became more naked and active and $\mathrm{Hg}$ (II) ions were easier to be adsorbed. Notably, adsorption experiments were not conducted when the $\mathrm{pH}$ value was higher than 7.0 , because the metal ions could precipitate or form the hydroxyl complexes [20, 44]. Given the above description and results from Figure 2, initial $\mathrm{pH}$ 6.0 was selected as the optimum value for $\mathrm{Hg}$ (II) adsorption.

3.3. Adsorption Kinetics. The effect of contact time on the adsorption of PACA nanofibrils for $\mathrm{Hg}$ (II) ion was shown in Figure 3. It is apparent that the adsorption of $\mathrm{Hg}$ (II) is a timedependent process. The adsorption occurred very rapidly

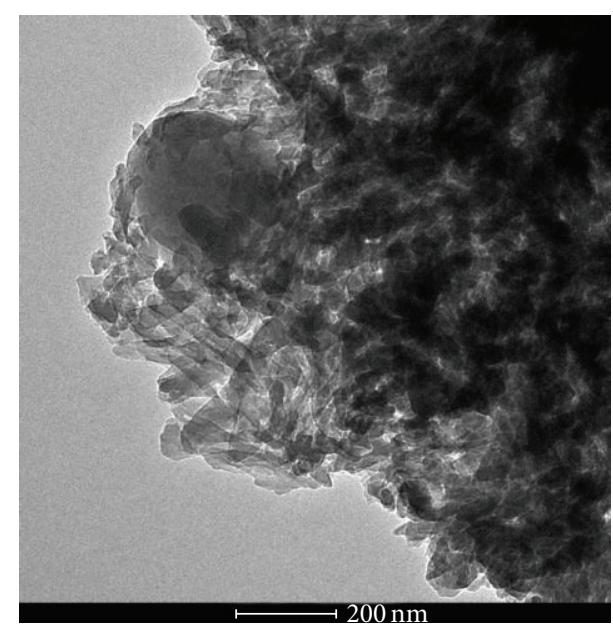

FIgURE 4: TEM photograph of PACA nanofibrils upon adsorption of $\mathrm{Hg}(\mathrm{II})$.

within the initial $20 \mathrm{~min}$, in which $83 \%$ adsorptivity of $\mathrm{Hg}$ (II) ion was achieved. Such rapid adsorption is not only because of a great number of various functional groups including $-\mathrm{NH}-,-\mathrm{N}=,-\mathrm{NH}_{2},-\mathrm{C}=\mathrm{O}$, and $-\mathrm{Cl}$ on the PACA nanofibrils but also because of their high porosity which is confirmed by low density (apparent density: $0.375 \mathrm{~g} \mathrm{~cm}^{-3}$; bulk density: $\left.0.649 \mathrm{~g} \mathrm{~cm}^{-3}\right)$ and high specific area $\left(35 \mathrm{~m}^{2} \mathrm{~g}^{-1}\right)$ [22]. Also, this could be reasonably attributed to the absence of internal diffusion resistance [45]. At the same time, the adsorption of $\mathrm{Hg}$ (II) fitted well the pseudo-second-order kinetic equation (inserted curve in Figure 3 ); the rate constant $\left(k_{\mathrm{ad}}\right)$ was calculated to be 2.277 .

3.4. Adsorption Mechanism. The surface area of PACA nanoadsorbents decreased from 35 to $31 \mathrm{~m}^{2} \mathrm{~g}^{-1}$ after adsorption of $\mathrm{Hg}(\mathrm{II})$. The decrease in surface area initially implied that the metal adsorptions really happened. TEM observations showed that the PACA nanofibrils seemed to be slightly aggregated after $\mathrm{Hg}(\mathrm{II})$ adsorbing (Figure 4). Even so, the aggregated microparticles of PACA could be turned into nanoparticles (related TEM photograph not shown) by intense ultrasonic dispersion after metal recycling, indicating that the PACA nanofibrils could easily be regenerated.

The adsorption mechanism of PACA nanofibrils for $\mathrm{Hg}$ (II) was further studied by FT-IR and XPS spectral analyses (Figures 5-7). The FT-IR wavenumbers corresponding to different functional groups were summarized in Table S1 of the Supplementary Information (SI) available online at http:// dx.doi.org/10.1155/2016/7245829. After adsorption of $\mathrm{Hg}$ (II) ions, the FT-IR stretching peaks at 3455,1642 , and $737 \mathrm{~cm}^{-1}$ due to $-\mathrm{NH}-,-\mathrm{C}=\mathrm{O}$, and $\mathrm{C}-\mathrm{H}$ groups shifted to lower energy by approximately 9,8 , and $2-5 \mathrm{~cm}^{-1}$, respectively, and the peak at $1259 \mathrm{~cm}^{-1}$ due to $\mathrm{C}-\mathrm{CO}-\mathrm{C}$ group became undetectable, indicating that some binding interaction formed between polymers and metal ions [46].

It is known that the main adsorption sites for $\mathrm{Hg}$ (II) ion are the nitrogen and oxygen atoms present in the polymer chains because they have several lone pairs of electrons that 


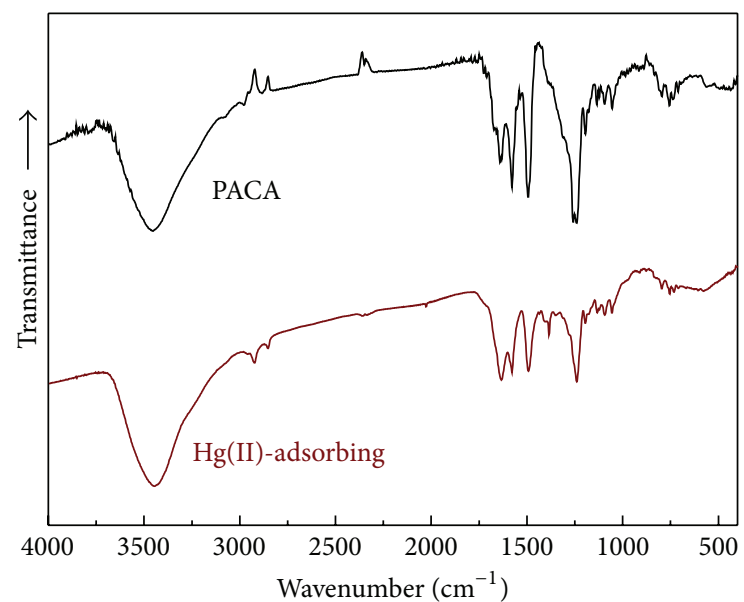

FIGURE 5: FT-IR spectra of PACA polymer and PACA salt after adsorption of $\mathrm{Hg}$ (II) at an initial $\mathrm{Hg}$ (II) concentration of $10 \mathrm{mmol} \mathrm{L}^{-1}$ with adsorbent dosage of $1.6 \mathrm{~g} \mathrm{~L}^{-1}$ at $25^{\circ} \mathrm{C}$.

can efficiently bind a metal ion to form a metal complex, as shown in Scheme 1. The $-\mathrm{NH}-\left(\right.$ or $\left.-\mathrm{N}=/-\mathrm{NH}_{2}\right),-\mathrm{C}=\mathrm{O}$, and $\mathrm{C}-\mathrm{CO}-\mathrm{C}$ groups were most likely to act as the adsorption sites for $\mathrm{Hg}(\mathrm{II})$. The reason is that soft acid of $\mathrm{Hg}(\mathrm{II})$ ion offers high affinity toward soft bases of $-\mathrm{C}=\mathrm{O}$ and $\mathrm{C}-\mathrm{CO}-\mathrm{C}$ groups and middle-soft bases of $-\mathrm{NH}-,-\mathrm{N}=$, and $-\mathrm{NH}_{2}$ groups. Also, aromatic $\mathrm{C}-\mathrm{H}$ bonds would be another adsorption site via formation of charge transfer between $\pi$-electron-rich anthraquinone and electron-poor $\mathrm{Hg}(\mathrm{II})$ ion.

XPS technique was applied to identify the interaction between $\mathrm{Hg}(\mathrm{II})$ ions and PACA nanoadsorbents (Figure 6). Several strong peaks with binding energies (BEs) of 200.3, $284.9,399.4$, and $531.3 \mathrm{eV}$ corresponded to $\mathrm{Cl}_{2 \mathrm{p}}, \mathrm{C}_{1 \mathrm{~s}}, \mathrm{~N}_{1 \mathrm{~s}}$, and $\mathrm{O}_{1 \mathrm{~s}}$ orbitals, respectively, which existed in pristine PACA nanofibrils. Upon adsorption of $\mathrm{Hg}(\mathrm{II})$ ion, a new peak with $\mathrm{BE}$ of $101.7 \mathrm{eV}\left(\mathrm{Hg}_{4 \mathrm{f}}\right)$ appeared. The results further indicated that $\mathrm{Hg}(\mathrm{II})$ ion was adsorbed onto PACA.

High-resolution XPS spectra of $\mathrm{O}_{1 \mathrm{~s}}, \mathrm{~N}_{1 \mathrm{~s}}, \mathrm{C}_{1 \mathrm{~s}}$, and $\mathrm{Cl}_{2 \mathrm{p}}$ core levels are shown in Figure 7. The detailed BEs were summarized in Table S2. It is known that when the chemical environment of atoms in a blend is perturbed by specific interaction, their binding energy will be varied, or a peak with a higher binding energy will be produced in the XPS spectrum [47]. The $\mathrm{O}_{1 \mathrm{~s}}$ XPS spectra of pristine PACA displayed three peaks at BEs of 531.3, 532.5, and $536.2 \mathrm{eV}$ (Figure $7(\mathrm{a})$ ), attributed to $-\mathrm{O}-,-\mathrm{C}=\mathrm{O}$, and quinone moieties [48], respectively. After $\mathrm{Hg}$ (II) adsorption, the $\mathrm{BEs}$ of $\mathrm{O}_{1 \text { s }}$ for $-\mathrm{C}=\mathrm{O}$ and quinone moieties decreased by 0.2 and $0.5 \mathrm{eV}$, respectively. These shifts may be due to a decrease in the electric density around oxygen atoms resulting from the electron draining to $\mathrm{Hg}(\mathrm{II})$ [49], reflecting the intense interaction between oxygen atoms and $\mathrm{Hg}$ (II) ions. These results along with FT-IR spectral analyses signified that $\mathrm{Hg}(\mathrm{II})-\mathrm{O}$ coordination was formed due to the electron-donating ability of the oxygen atoms (Scheme 1, dash arrows).

The high-resolution $\mathrm{N}_{1 \mathrm{~s}}$ XPS spectra of PACA upon adsorption of $\mathrm{Hg}(\mathrm{II})$ are shown in Figure 7 (b). The pristine PACA exhibited a single peak located at $399.4 \mathrm{eV}$ due to

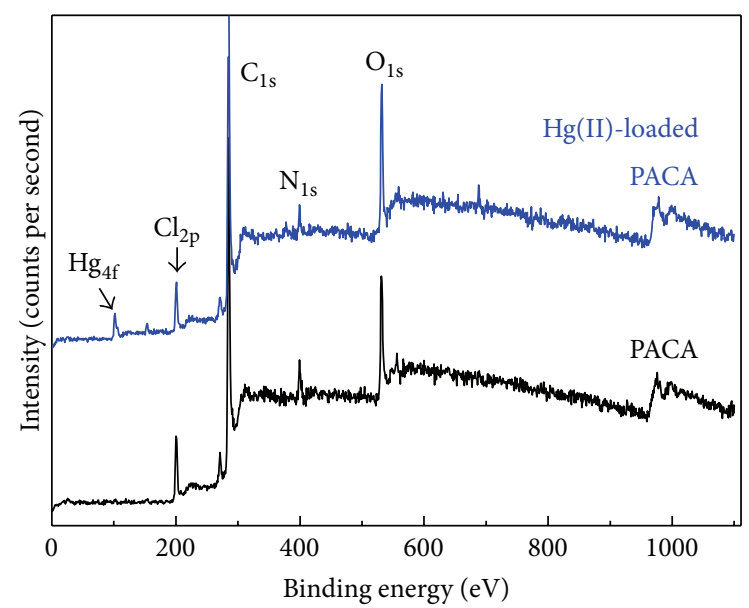

FIGURE 6: XPS wide scan spectra of PACA and Hg(II)-loaded PACA.

amine nitrogen (-NH-). After adsorption of $\mathrm{Hg}(\mathrm{II})$, however, a new peak with a higher BE of $402.1 \mathrm{eV}$ appeared. Similar peaks were also found in previously reported adsorbents [48]. The reason is that some nitrogen atoms existed in a more oxidized state on the surface of PACA nanofibrils after interacting with $\mathrm{Hg}(\mathrm{II})$, forming $\mathrm{Hg}(\mathrm{II}) \cdots \mathrm{NH}$ - complex (Scheme 1, dash arrows). The nitrogen atoms would then donate their lone pairs of electrons to the coordination bonds between nitrogen and $\mathrm{Hg}(\mathrm{II})$. Electron cloud density in nitrogen atoms was finally reduced, producing an additional peak with a higher $\mathrm{BE}$ [50]. The $\mathrm{N}_{1 s}$ XPS spectra provide evidence of $\mathrm{Hg}$ (II) ions binding to nitrogen atoms.

The high-resolution $\mathrm{C}_{1 \mathrm{~s}}$ XPS spectra of PACA upon adsorption of $\mathrm{Hg}(\mathrm{II})$ are shown in Figure $7(\mathrm{c})$. Pristine PACA showed four peaks at 284.9, 286.3, 287.6, and $291.8 \mathrm{eV}$, attributed to $\mathrm{C}-\mathrm{C}, \mathrm{C}-\mathrm{O}, \mathrm{C}=\mathrm{O}$, and large $\pi$ bonds [51], respectively. The results indicate that the large $\pi$ bonds also played a key role in the adsorption of $\mathrm{Hg}(\mathrm{II})$ ions (Scheme 1, dash lines). Additionally, the high-resolution $\mathrm{Hg}_{4 \mathrm{f}}$ spectra (Figure S1, SI) exhibited two peaks at 101.7 and $105.4 \mathrm{eV}$ assigned to $\mathrm{Hg} 4 \mathrm{f}_{7 / 2}$ and $\mathrm{Hg} 4 \mathrm{f}_{5 / 2}$, respectively. The presence of $\mathrm{Hg} 4 \mathrm{f}_{7 / 2}$ peak at $101.7 \mathrm{eV}$ indicated that $\mathrm{Hg}^{2+}$ formed a complex with $-\mathrm{NH}-,-\mathrm{N}=,-\mathrm{NH}_{2},-\mathrm{C}=\mathrm{O}$, and large $\pi$ bonds [52].

The high-resolution $\mathrm{Cl}_{2 \mathrm{p}}$ XPS spectra of PACA, however, exhibited neglectable changes after adsorption of $\mathrm{Hg}$ (II) (Figure 7(d)). Previously theoretical chemistry calculations based on density functional theory (DFT) indicated that the chlorine atoms in PACA molecules were slightly positively charged [37], so they differ from traditional electrondonating groups such as nitrogen, sulfur, and oxygen atoms. The "positive chlorine" would partly repulse the positive $\mathrm{Hg}$ (II) ion.

Based on the FT-IR, XPS, and DFT analyses, we conclude that chlorine atoms did not contribute to the chemical adsorption of metal ions. The adsorption mechanism could be that negatively charged functional groups including $-\mathrm{NH}-,-\mathrm{N}=,-\mathrm{NH}_{2},-\mathrm{C}=\mathrm{O}$, and large $\pi$ bonds in PACA nanofibrils coordinated with $\mathrm{Hg}(\mathrm{II})$ ions to form a stable complex (Scheme 1), leading to the superb adsorption 


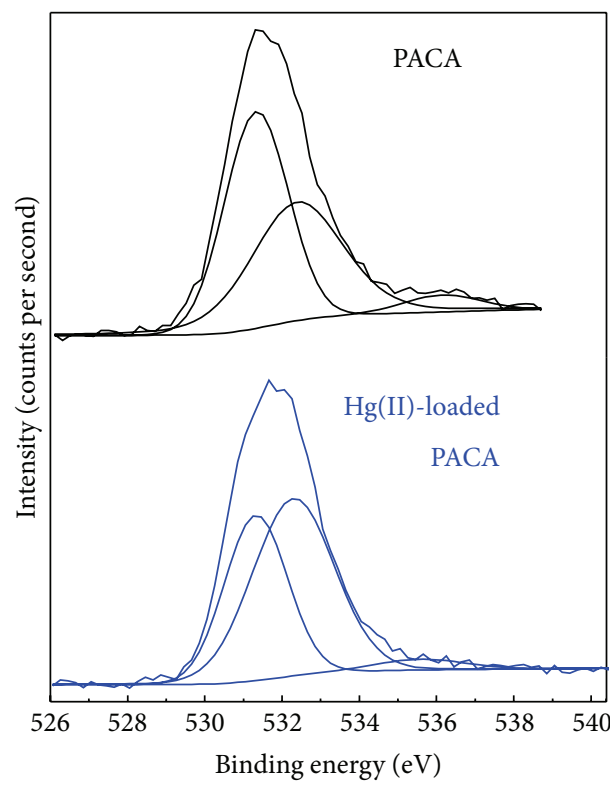

(a)

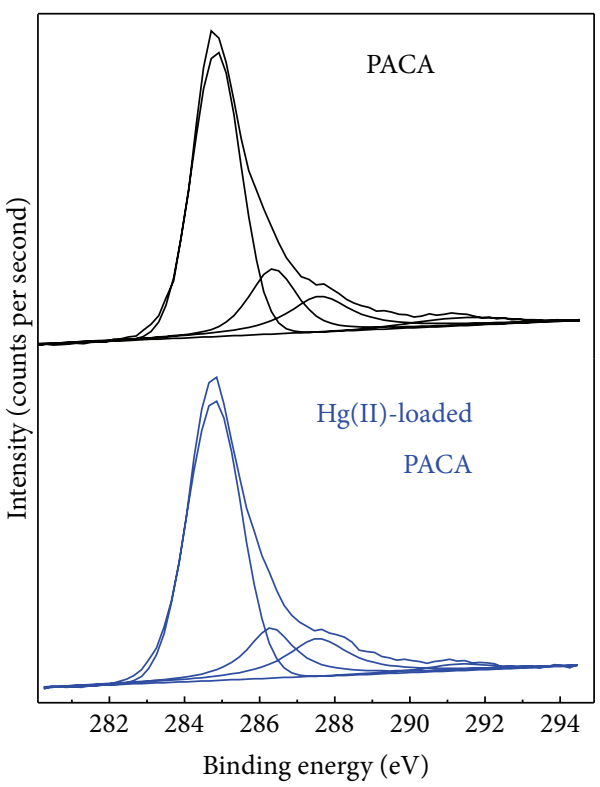

(c)

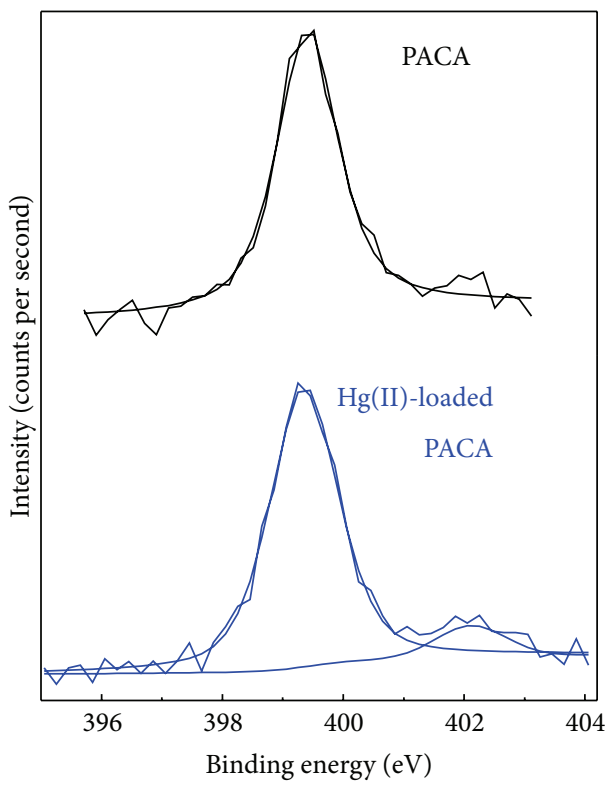

(b)

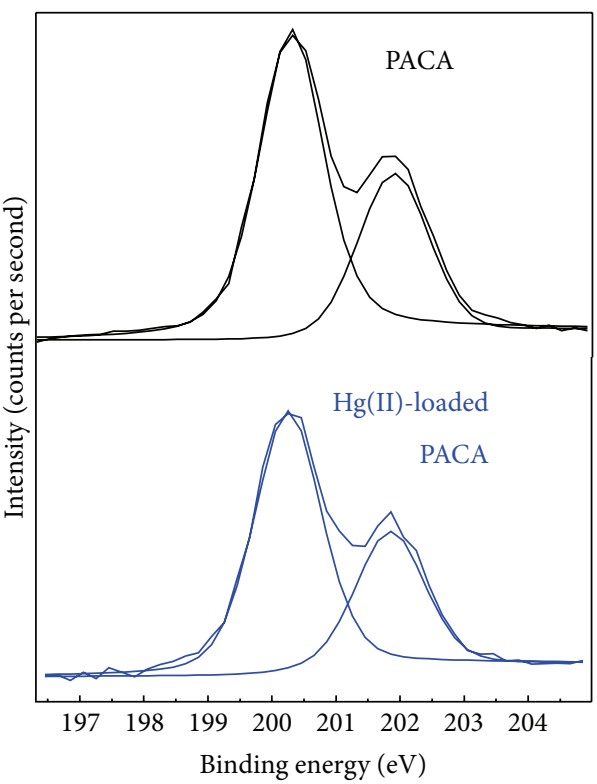

(d)

FIGURE 7: High-resolution XPS spectra of (a) $\mathrm{O}_{1 \mathrm{~s}}$, (b) $\mathrm{N}_{1 \mathrm{~s}}$, (c) $\mathrm{C}_{1 \mathrm{~s}}$, and (d) $\mathrm{Cl}_{2 \mathrm{p}}$.

capacity. Additionally, $\mathrm{pH}$ changes in metal ion solutions before and after the addition of PACA nanoadsorbents were monitored to understand the adsorption mechanism better [53]. After adsorption, the $\mathrm{pH}$ values of $\mathrm{Hg}(\mathrm{II})$ solutions showed unapparent changes. Accordingly, the ion exchange mechanism was not included in the adsorption of $\mathrm{Hg}$ (II) ion.

3.5. Adsorption Isotherms. In order to reveal the adsorption behavior and to estimate the adsorption capacity, adsorption isotherms have been studied. Since Freundlich and Langmuir isotherms were most commonly used to describe the adsorption isotherms [54], the adsorption processes of $\mathrm{Hg}$ (II) on
PACA nanofibrils were tested with Freundlich (see (4)) and Langmuir (see (5)) isotherm models:

$$
\begin{aligned}
\log Q & =\log K_{F}+\frac{1}{n} \log C_{e}, \\
\frac{C_{e}}{Q} & =\frac{1}{b Q_{m}}+\frac{C_{e}}{Q_{m}},
\end{aligned}
$$

where $Q\left(\mathrm{mmol} \mathrm{g}^{-1}\right)$ is the adsorption capacity based on the dry weight of nanoadsorbent, $C_{e}\left(\mathrm{mmol} \mathrm{L}^{-1}\right)$ is the equilibrium concentration in solution, $K_{F}\left[\left(\mathrm{mmol} \mathrm{g}^{-1}\right)\left(\mathrm{L} \mathrm{mmol}^{-1}\right)^{1 / n}\right]$ is the binding energy constant reflecting the affinity of 


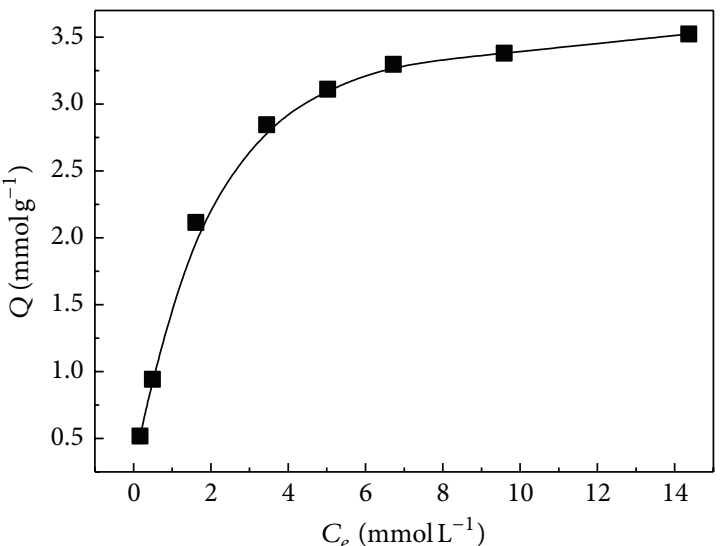

(a)

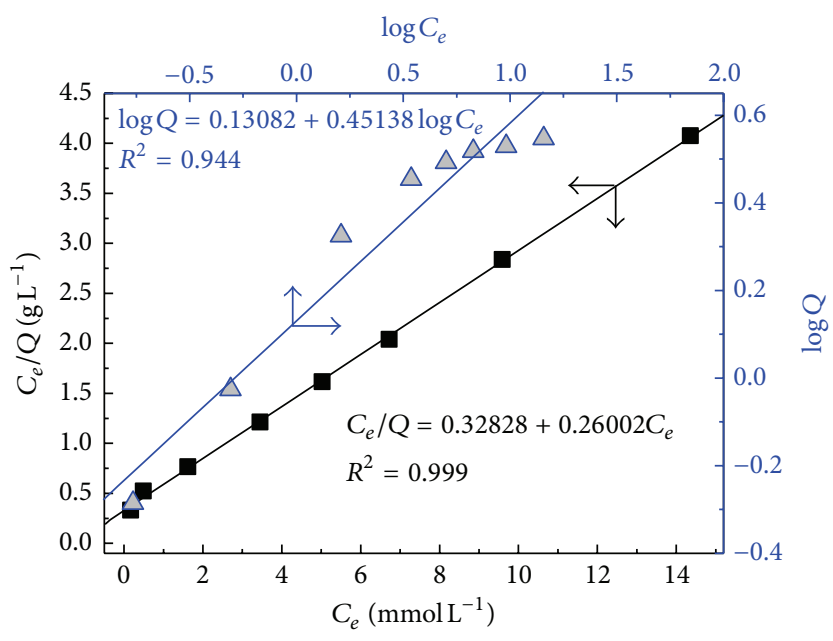

(b)

FIgURE 8: (a) Adsorption isotherm of $\mathrm{Hg}(\mathrm{II})$ on the PACA nanofibrils at an initial metal ion concentration from 1.0 to $20 \mathrm{mmol} \mathrm{L}^{-1}$, adsorbent dose of $1.6 \mathrm{~g} \mathrm{~L}^{-1}, \mathrm{pH}$ of 6.0 , and temperature of $25^{\circ} \mathrm{C}$ for $24 \mathrm{~h}$. (b) Linearized Freundlich and Langmuir isotherms for adsorption of $\mathrm{Hg}(\mathrm{II})$.

the PACA nanofibrils for metal ions, $n$ is the Freundlich constant, $Q_{m}\left(\mathrm{mmol} \mathrm{g}^{-1}\right)$ is the maximum adsorption capacity, and $b\left(\mathrm{~L} \mathrm{mmol}^{-1}\right)$ is the Langmuir adsorption equilibrium constant.

The adsorption isotherm was shown in Figure 8(a). The initial concentration of $\mathrm{Hg}$ (II) was in the range of 1.0$20 \mathrm{mmol} \mathrm{L}^{-1}$. As shown, with increasing metal ion concentration, the adsorption capacity increased correspondingly. This is probably due to a relatively higher driving force for mass transfer [55]. As shown in Figure 8(b), the plot of $C_{e} / Q$ versus $C_{e}$ yielded a straight line with a coefficient $\left(R^{2}\right)$ of 0.999 , but that of $\log C_{e}$ versus $\log Q$ yielded a curve with a coefficient $\left(R^{2}\right)$ of only 0.944 , revealing that the adsorption obeyed Langmuir isotherm rather than Freundlich one. From the slope and intercept, the values of $Q_{m}$ and $b$ were calculated to be $3.846 \mathrm{mmol} \mathrm{g}^{-1}$ and $0.792 \mathrm{~L} \mathrm{mmol}^{-1}$, respectively. The maximum adsorption capacity of PACA nanofibrils for $\mathrm{Hg}$ (II) is significantly higher than most of those reported adsorbents including polymers, inorganics, and modified inorganics, as shown in Table S3 of the SI. Note that the maximum adsorption capacities usually depend on the following two characteristics: large surface area and polyfunctional groups. Large surface area ensures the sufficient contact of the solid adsorbent with metal ions in aqueous solutions, while polyfunctional groups provide a large number of active sites for the adsorption reaction. An efficient adsorbent should optimally combine these two characteristics.

3.6. Reuse of PACA Nanofibrils. To investigate the feasibility of reusing the nanofibrils, desorption experiments were conducted. The desorption efficiency of the PACA nanofibrils was evaluated by several eluents including $\mathrm{HNO}_{3}$, thiourea, EDTA, and their combined aqueous solutions. When $0.50 \mathrm{~mol} \mathrm{~L}^{-1} \mathrm{HNO}_{3}, 3.0 \%$ thiourea, $1.0 \%$ thiourea in $0.50 \mathrm{~mol} \mathrm{~L}^{-1} \mathrm{HNO}_{3}, 3.0 \%$ thiourea in $0.50 \mathrm{~mol} \mathrm{~L}^{-1} \mathrm{HNO}_{3}$, $3.0 \%$ EDTA, $1.0 \%$ EDTA in $0.50 \mathrm{~mol} \mathrm{~L}^{-1} \mathrm{HNO}_{3}$, and $3.0 \%$
EDTA in $0.50 \mathrm{~mol} \mathrm{~L}^{-1} \mathrm{HNO}_{3}$ were used, the desorption ratios were found to be $42.9,59.3,80.5,88.0,74.2,90.6$, and $99.9 \%$, respectively. We found that $3.0 \%$ EDTA in $0.50 \mathrm{~mol} \mathrm{~L}^{-1}$ $\mathrm{HNO}_{3}$ was the best eluent and then used it to regenerate the nanofibrils. This is due to the fact that EDTA is a strong six-tridentate ligand containing two imino and four carboxyl groups, and the distance between these groups is enough long, which facilitates EDTA to form highly stable chelates with common transition metals. For instance, the stability constants for the complex ions of $[\mathrm{Hg}(\mathrm{EDTA})]^{2-}$ and $[\mathrm{Pb}(\mathrm{EDTA})]^{2-}$ are as high as $6.3 \times 10^{21}$ and $1.0 \times 10^{18}$, respectively [56]. On the other hand, the highly acidic environment is favorable for the desorption of heavy metal ions from the PACA nanofibrils, without significantly reducing the extremely strong complexing ability of EDTA. The adsorbent was reused in five successive adsorption-desorption cycles as can be seen in Figure 9, indicating a slight loss $(1.8 \%)$ in the desorption capacity (metal recovery) for $\mathrm{Hg}$ (II) compared to the initial cycle (98.1-99.6\% versus $99.9 \%$ ), revealing a good regeneration capacity of the adsorbent. Besides, the $\mathrm{Hg}(\mathrm{II})$ adsorption capacity decreased from $2.08 \mathrm{mmol} \mathrm{g}^{-1}$ in initial cycle to $1.97 \mathrm{mmol} \mathrm{g}^{-1}$ in final cycle, which revealed a slight loss (5.3\%) of adsorption capability. The data suggested that PACA nanofibrils were suitable for repeated use for far more than five times. These results suggest that PACA adsorbents were highly recyclable.

3.7. Practicability of PACA Nanosorbent for Purifying Ambient Wastewater. In order to evaluate the practicability of PACA nanosorbent for purifying actual wastewater, a batch experiment was conducted on chloralkali wastewater. The characteristics of chloralkali wastewater are summarized in Table S4 of the SI. As the results show, chloralkali wastewater contains a high concentration of different ions, which may interfere with adsorption of $\mathrm{Hg}(\mathrm{II})$ ion on the adsorbents. Thus, the selectivity of the adsorbent is especially important. When an 


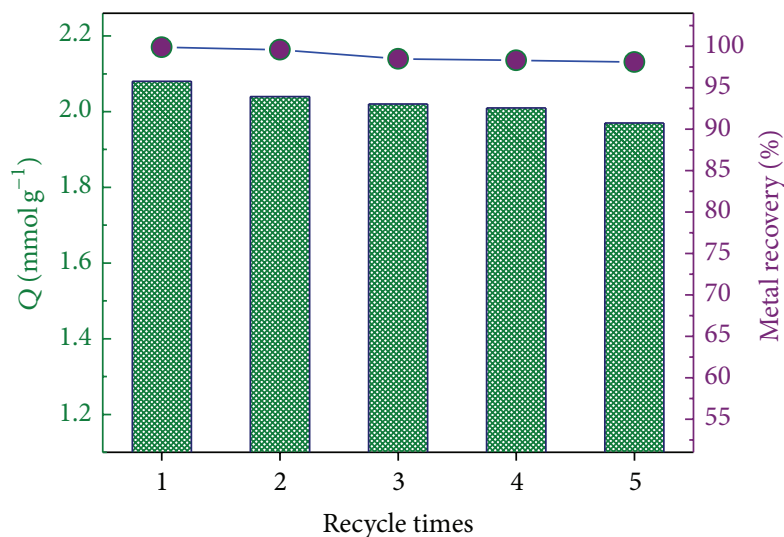

FIGURE 9: Variation of the capacity (columns) of $\mathrm{Hg}$ (II) adsorption onto PACA nanofibrils and metal recovery (symbols) in successive cycles. Initial concentration of $\mathrm{Hg}(\mathrm{II})$ was $5.0 \mathrm{mmol} \mathrm{L}^{-1}$.

adsorbent dose of $1.6 \mathrm{~g} \mathrm{~L}^{-1}$ was applied, PACA nanoadsorbent exhibited a very high capability for adsorption of mercury ions $(98.4 \%)$ from chloralkali wastewater. After only oneoff adsorption, the $\mathrm{Hg}(\mathrm{II})$ concentration reduced from 97.3 to $1.56 \mu \mathrm{g} \mathrm{L}^{-1}$ and thus the quality of the water is greatly enhanced, which satisfactorily meets the discharge standard of pollutants for municipal wastewater treatment plant proposed by the US EPA.

\section{Conclusions}

Porous poly(1-amino-5-chloroanthraquinone) (PACA) nanofibrils synthesized by interfacial polymerization demonstrated high efficiency to remove $\mathrm{Hg}(\mathrm{II})$ ion from contaminated water. Adsorption mechanism investigation indicated that high surface area and strong affinity of $-\mathrm{NH}-,-\mathrm{N}=,-\mathrm{NH}_{2}$, $-\mathrm{C}=\mathrm{O}$, and large $\pi$ bonds of PACA nanofibrils mainly determined the metal ion removal efficiency. Adsorption kinetics studies showed that the adsorption of $\mathrm{Hg}$ (II) achieved equilibrium within two hours and followed the pseudo-secondorder rate due to the strong chemical adsorption process; the equilibrium isotherms obeyed the Langmuir adsorption. PACA nanofibrils have been prepared by one-pot synthesis method in the present work, and relatively cheap ACA monomers, sodium hypochlorite, nitrobenzene, and alcohol were used as raw materials, respectively, while nitrobenzene was recycled for repeated use. PACA nanofibrils were highly recyclable and capable of efficiently removing $\mathrm{Hg}$ (II) ion after being used five times. The reagents (including nitric acid and EDTA) used in the recovery of PACA are also cheap. It is concluded that the PACA nanofibrils offer low cost and sustainable adsorbents for water purification.

\section{Competing Interests}

The authors declare that there are no competing interests regarding the publication of this paper.

\section{Acknowledgments}

This research is funded by the National Natural Science Foundation of China (Grants 51363012, 21262020, and 51203090), the Applied Basic Research Foundation of Yunnan Province (Grant KKSY201232041), and the Analysis and Testing Foundation of Kunming University of Science and Technology (Grants 2014ZX01, 2014ZX03, 2014ZX05, and 20151022).

\section{References}

[1] Z. Li, L. Wu, H. Liu, H. Lan, and J. Qu, "Improvement of aqueous mercury adsorption on activated coke by thiol-functionalization," Chemical Engineering Journal, vol. 228, pp. 925-934, 2013.

[2] J. H. Pavlish, M. J. Holmes, S. A. Benson, C. R. Crocker, and K. C. Galbreath, "Application of sorbents for mercury control for utilities burning lignite coal," Fuel Processing Technology, vol. 85, no. 6-7, pp. 563-576, 2004.

[3] T. Wajima and K. Sugawara, "Adsorption behaviors of mercury from aqueous solution using sulfur-impregnated adsorbent developed from coal," Fuel Processing Technology, vol. 92, no. 7, pp. 1322-1327, 2011.

[4] B.-J. Kim, K.-M. Bae, K.-H. An, and S.-J. Park, "Elemental mercury adsorption behaviors of chemically modified activated carbons," Bulletin of the Korean Chemical Society, vol. 32, no. 4, pp. 1321-1326, 2011.

[5] M. F. Yardim, T. Budinova, E. Ekinci, N. Petrov, M. Razvigorova, and V. Minkova, "Removal of mercury (II) from aqueous solution by activated carbon obtained from furfural," Chemosphere, vol. 52, no. 5, pp. 835-841, 2003.

[6] J. Wang, B. L. Deng, H. Chen, X. R. Wang, and J. Z. Zheng, "Removal of aqueous $\mathrm{Hg}(\mathrm{II})$ by polyaniline: sorption characteristics and mechanisms," Environmental Science \& Technology, vol. 43, no. 14, pp. 5223-5228, 2009.

[7] F.-S. Zhang, J. O. Nriagu, and H. Itoh, "Mercury removal from water using activated carbons derived from organic sewage sludge," Water Research, vol. 39, no. 2-3, pp. 389-395, 2005.

[8] A. A. Atia, A. M. Donia, and W. A. Al-Amrani, "Effect of amine type modifier on the uptake behaviour of silica towards mercury(II) in aqueous solution," Desalination, vol. 246, no. 1-3, pp. 257-274, 2009.

[9] L. Zhou, Z. Liu, J. Liu, and Q. Huang, "Adsorption of Hg(II) from aqueous solution by ethylenediamine-modified magnetic crosslinking chitosan microspheres," Desalination, vol. 258, no. 1-3, pp. 41-47, 2010.

[10] Q. Li, L. Sun, Y. Zhang, Y. Qian, and J. Zhai, "Characteristics of equilibrium, kinetics studies for adsorption of $\mathrm{Hg}$ (II) and Cr(VI) by polyaniline/humic acid composite," Desalination, vol. 266, no. 1-3, pp. 188-194, 2011.

[11] X. C. Lu, J. C. Jiang, K. Sun, J. B. Wang, and Y. P. Zhang, "Influence of the pore structure and surface chemical properties of activated carbon on the adsorption of mercury from aqueous solutions," Marine Pollution Bulletin, vol. 78, no. 1-2, pp. 69-76, 2014.

[12] N. Asasian, T. Kaghazchi, and M. Soleimani, "Elimination of mercury by adsorption onto activated carbon prepared from the biomass material," Journal of Industrial and Engineering Chemistry, vol. 18, no. 1, pp. 283-289, 2012.

[13] A. Košak, A. Lobnik, and M. Bauman, "Adsorption of mercury(II), lead(II), cadmium(II) and zinc(II) from aqueous solutions using mercapto-modified silica particles," International 
Journal of Applied Ceramic Technology, vol. 12, no. 2, pp. 461472, 2015.

[14] A. A. A. Hamid, C. P. Tripp, A. E. Bruce, and M. R. M. Bruce, "Application of structural analogs of dimercaptosuccinic acidfunctionalized silica nanoparticles (DMSA-[silica]) to adsorption of mercury, cadmium, and lead," Research on Chemical Intermediates, vol. 37, no. 7, pp. 791-810, 2011.

[15] R. Herrero, P. Lodeiro, C. Rey-Castro, T. Vilariño, and M. E. S. de Viceñte, "Removal of inorganic mercury from aqueous solutions by biomass of the marine macroalga Cystoseira baccata," Water Research, vol. 39, no. 14, pp. 3199-3210, 2005.

[16] N. J. Barrow and V. C. Cox, "The effects of $\mathrm{pH}$ and chloride concentration on mercury sorption. I. By goethite," Journal of Soil Science, vol. 43, no. 2, pp. 295-304, 1992.

[17] Q. H. Wang, X. J. Chang, D. D. Li, Z. Hu, R. J. Li, and Q. He, "Adsorption of chromium(III), mercury(II) and lead(II) ions onto 4-aminoantipyrine immobilized bentonite," Journal of Hazardous Materials, vol. 186, no. 2-3, pp. 1076-1081, 2011.

[18] Y. Kim and Y. J. Lee, "Characterization of mercury sorption on hydroxylapatite: batch studies and microscopic evidence for adsorption," Journal of Colloid and Interface Science, vol. 430, pp. 193-199, 2014.

[19] Y. Liu, Y. Li, and X.-P. Yan, "Preparation, characterization, and application of L-cysteine functionalized multiwalled carbon nanotubes as a selective sorbent for separation and preconcentration of heavy metals," Advanced Functional Materials, vol. 18, no. 10, pp. 1536-1543, 2008.

[20] M. J. Shadbad, A. Mohebbi, and A. Soltani, "Mercury(II) removal from aqueous solutions by adsorption on multi-walled carbon nanotubes," Korean Journal of Chemical Engineering, vol. 28, no. 4, pp. 1029-1034, 2011.

[21] R. Tang, Q. Li, L. Ding, H. Cui, and J. Zhai, "Reactive sorption of mercury(II) on to poly(m-phenylenediamine) microparticles," Environmental Technology, vol. 33, no. 3, pp. 341-348, 2012.

[22] M.-R. Huang, S.-J. Huang, and X.-G. Li, "Facile synthesis of polysulfoaminoanthraquinone nanosorbents for rapid removal and ultrasensitive fluorescent detection of heavy metal ions," Journal of Physical Chemistry C, vol. 115, no. 13, pp. 5301-5315, 2011.

[23] G. Karthikeyan, K. Anbalagan, and N. M. Andal, "Adsorption dynamics and equilibrium studies of Zn (II) onto chitosan," Journal of Chemical Sciences, vol. 116, no. 2, pp. 119-127, 2004.

[24] K. Hristovski, A. Baumgardner, and P. Westerhoff, "Selecting metal oxide nanomaterials for arsenic removal in fixed bed columns: from nanopowders to aggregated nanoparticle media," Journal of Hazardous Materials, vol. 147, no. 1-2, pp. 265274, 2007.

[25] L. Li, M. H. Fan, R. C. Brown et al., "Synthesis, properties, and environmental applications of nanoscale iron-based materials: a review," Critical Reviews in Environmental Science and Technology, vol. 36, no. 5, pp. 405-431, 2006.

[26] Y. Sun, X. Ding, Z. Zheng, X. Cheng, X. Hu, and Y. Peng, "A novel approach to magnetic nanoadsorbents with high binding capacity for bovine serum albumin," Macromolecular Rapid Communications, vol. 28, no. 3, pp. 346-351, 2007.

[27] W.-X. Zhang, "Nanoscale iron particles for environmental remediation: an overview," Journal of Nanoparticle Research, vol. 5, no. 3-4, pp. 323-332, 2003.

[28] A. Vaseashta, M. Vaclavikova, S. Vaseashta, G. Gallios, P. Roy, and O. Pummakarnchana, "Nanostructures in environmental pollution detection, monitoring, and remediation," Science and Technology of Advanced Materials, vol. 8, no. 1-2, pp. 47-59, 2007.
[29] Y. C. Sharma, V. Srivastava, V. K. Singh, S. N. Kaul, and C. H. Weng, "Nano-adsorbents for the removal of metallic pollutants from water and wastewater," Environmental Technology, vol. 30, no. 6, pp. 583-609, 2009.

[30] C.-Y. Cao, J. Qu, F. Wei, H. Liu, and W.-G. Song, "Superb adsorption capacity and mechanism of flowerlike magnesium oxide nanostructures for lead and cadmium ions," ACS Applied Materials \& Interfaces, vol. 4, no. 8, pp. 4283-4287, 2012.

[31] Q. M. Peng, J. X. Guo, Q. R. Zhang et al., "Unique lead adsorption behavior of activated hydroxyl group in two-dimensional titanium carbide," Journal of the American Chemical Society, vol. 136, no. 11, pp. 4113-4116, 2014.

[32] L. R. Skubal and N. K. Meshkov, "Reduction and removal of mercury from water using arginine-modified $\mathrm{TiO}_{2}$," Journal of Photochemistry and Photobiology A: Chemistry, vol. 148, no. 1-3, pp. 211-214, 2002.

[33] F. He, W. Wang, J.-W. Moon, J. Howe, E. M. Pierce, and L. Liang, "Rapid removal of $\mathrm{Hg}$ (II) from aqueous solutions using thiolfunctionalized $\mathrm{Zn}$-doped biomagnetite particles," ACS Applied Materials and Interfaces, vol. 4, no. 8, pp. 4373-4379, 2012.

[34] I. Ojea-Jiménez, X. López, J. Arbiol, and V. Puntes, "Citratecoated gold nanoparticles as smart scavengers for mercury(II) removal from polluted waters," ACS Nano, vol. 6, no. 3, pp. 2253-2260, 2012.

[35] F. A. Pavan, A. C. Mazzocato, R. A. Jacques, and S. L. P. Dias, "Ponkan peel: a potential biosorbent for removal of $\mathrm{Pb}$ (II) ions from aqueous solution," Biochemical Engineering Journal, vol. 40, no. 2, pp. 357-362, 2008.

[36] S. J. Huang, P. Du, C. G. Min, Y. Z. Liao, H. Sun, and Y. Jiang, "Poly(1-amino-5-chloroanthraquinone): highly selective and ultrasensitive fluorescent chemosensor for ferric ion," Journal of Fluorescence, vol. 23, no. 4, pp. 621-627, 2013.

[37] S. J. Huang, C. G. Min, Y. Z. Liao et al., "Intrinsically conducting polyaminoanthraquinone nanofibrils: interfacial synthesis, formation mechanism and lead adsorbents," RSC Advances, vol. 4, no. 88, pp. 47657-47669, 2014.

[38] M. Hadavifar, N. Bahramifar, H. Younesi, and Q. Li, "Adsorption of mercury ions from synthetic and real wastewater aqueous solution by functionalized multi-walled carbon nanotube with both amino and thiolated groups," Chemical Engineering Journal, vol. 237, pp. 217-228, 2014.

[39] N. M. Bandaru, N. Reta, H. Dalal, A. V. Ellis, J. Shapter, and N. H. Voelcker, "Enhanced adsorption of mercury ions on thiol derivatized single wall carbon nanotubes," Journal of Hazardous Materials, vol. 261, pp. 534-541, 2013.

[40] P. Chand and Y. B. Pakade, "Removal of $\mathrm{Pb}$ from water by adsorption on apple pomace: equilibrium, kinetics, and thermodynamics studies," Journal of Chemistry, vol. 2013, Article ID 164575, 8 pages, 2013.

[41] F. Gode and E. Pehlivan, "A comparative study of two chelating ion-exchange resins for the removal of chromium(III) from aqueous solution," Journal of Hazardous Materials, vol. 100, no. 1-3, pp. 231-243, 2003.

[42] K. H. Reddy and A. R. Reddy, "Removal of heavy metal ions using the chelating polymers derived by the condensation of poly(3-hydroxy-4-acrtylphenl methacrylate) with different diamine," Journal of Applied Polymer Science, vol. 88, pp. 414421, 2003.

[43] C.-Y. Chen, M.-S. Lin, and K.-R. Hsu, "Recovery of Cu(II) and $\mathrm{Cd}(\mathrm{II})$ by a chelating resin containing aspartate groups," Journal of Hazardous Materials, vol. 152, no. 3, pp. 986-993, 2008. 
[44] Z. Elouear, J. Bouzid, N. Boujelben, M. Feki, F. Jamoussi, and A. Montiel, "Heavy metal removal from aqueous solutions by activated phosphate rock," Journal of Hazardous Materials, vol. 156, no. 1-3, pp. 412-420, 2008.

[45] S.-H. Huang and D.-H. Chen, "Rapid removal of heavy metal cations and anions from aqueous solutions by an aminofunctionalized magnetic nano-adsorbent," Journal of Hazardous Materials, vol. 163, no. 1, pp. 174-179, 2009.

[46] Y. Nuhoglu and E. Malkoc, "Thermodynamic and kinetic studies for environmentaly friendly $\mathrm{Ni}$ (II) biosorption using waste pomace of olive oil factory," Bioresource Technology, vol. 100, no. 8, pp. 2375-2380, 2009.

[47] C. Chen, L. Dong, and M. K. Cheung, "Preparation and characterization of biodegradable poly(l-lactide)/chitosan blends," European Polymer Journal, vol. 41, no. 5, pp. 958-966, 2005.

[48] Y.-T. Zhou, C. Branford-White, H.-L. Nie, and L.-M. Zhu, "Adsorption mechanism of $\mathrm{Cu}^{2+}$ from aqueous solution by chitosan-coated magnetic nanoparticles modified with $\alpha$ ketoglutaric acid," Colloids and Surfaces B: Biointerfaces, vol. 74, no. 1, pp. 244-252, 2009.

[49] H. M. Guan and X. S. Cheng, "Study of cobalt(II)-chitosan coordination polymer and its catalytic activity and selectivity for vinyl monomer polymerization," Polymers for Advanced Technologies, vol. 15, no. 1-2, pp. 89-92, 2004.

[50] X. Zhang and R. B. Bai, "Mechanisms and kinetics of humic acid adsorption onto chitosan-coated granules," Journal of Colloid and Interface Science, vol. 264, no. 1, pp. 30-38, 2003.

[51] Z.-H. Huang, X. Y. Zheng, W. Lv, M. Wang, Q.-H. Yang, and F. Y. Kang, "Adsorption of lead(II) ions from aqueous solution on low-temperature exfoliated graphene nanosheets," Langmuir, vol. 27, no. 12, pp. 7558-7562, 2011.

[52] R. S. Vieira, M. L. M. Oliveira, E. Guibal, E. RodríguezCastellón, and M. M. Beppu, "Copper, mercury and chromium adsorption on natural and crosslinked chitosan films: an XPS investigation of mechanism," Colloids and Surfaces A, vol. 374, no. 1-3, pp. 108-114, 2011.

[53] M.-R. Huang, H.-J. Lu, and X.-G. Li, "Synthesis and strong heavy-metal ion sorption of copolymer microparticles from phenylenediamine and its sulfonate," Journal of Materials Chemistry, vol. 22, no. 34, pp. 17685-17699, 2012.

[54] W. S. W. Ngah, C. S. Endud, and R. Mayanar, "Removal of copper(II) ions from aqueous solution onto chitosan and crosslinked chitosan beads," Reactive \& Functional Polymers, vol. 50, no. 2, pp. 181-190, 2002.

[55] H. Aydin, Y. Bulut, and Ç. Yerlikaya, "Removal of copper (II) from aqueous solution by adsorption onto low-cost adsorbents," Journal of Environmental Management, vol. 87, no. 1, pp. 37-45, 2008.

[56] B. T. Chen, Inorganic Chemistry, Higher Education Press, Beijing, China, 3rd edition, 1992. 

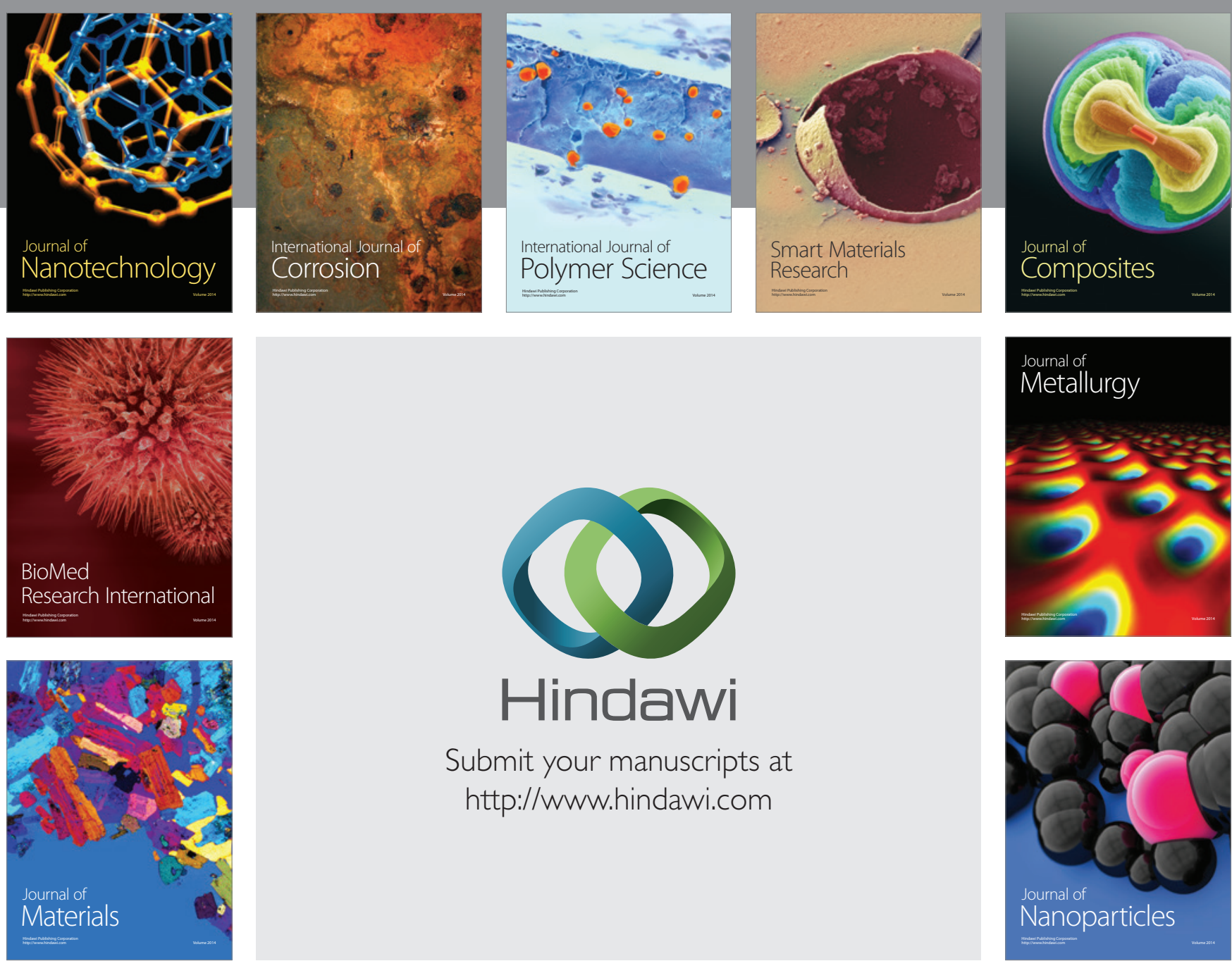

\section{Hindawi}

Submit your manuscripts at

http://www.hindawi.com

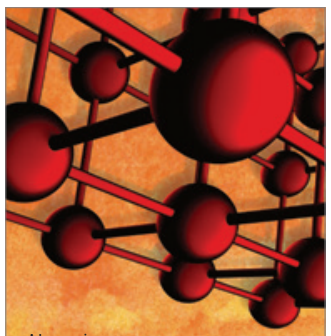

Materials Science and Engineering
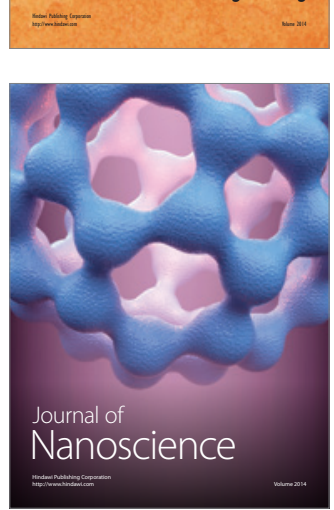
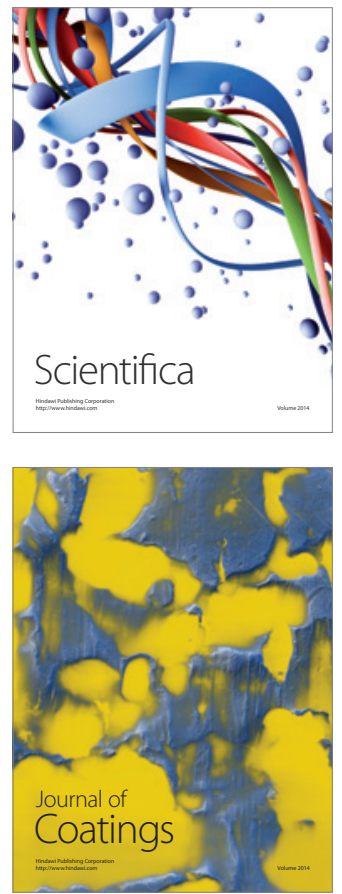
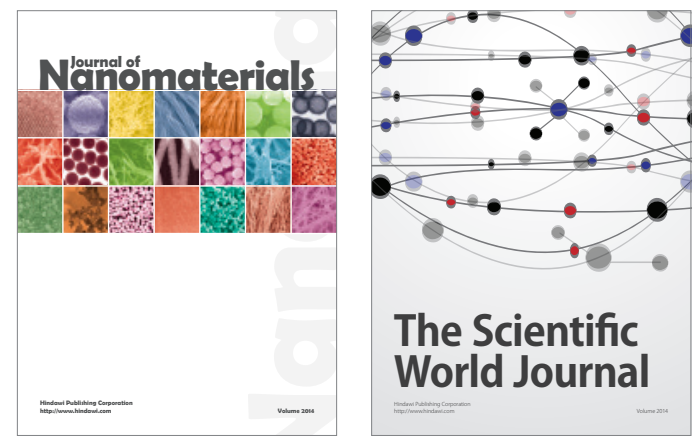

The Scientific World Journal
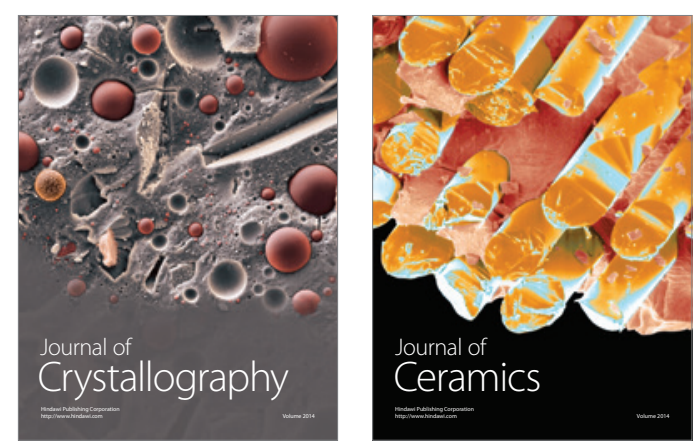
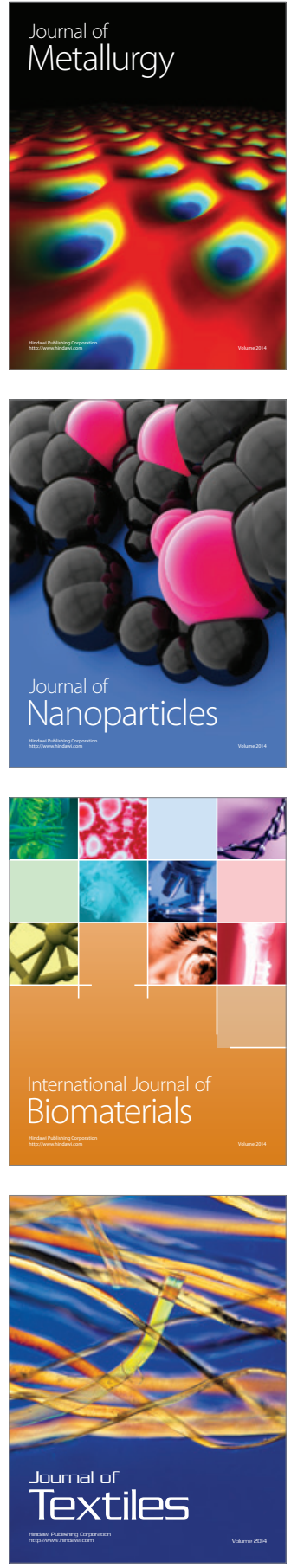